\title{
Derivation of salt content in salinized soil from hyperspectral reflectance data: A case study at Minqin Oasis, Northwest China
}

\author{
QIAN Tana ${ }^{1 *}$, Atsushi TSUNEKAWA ${ }^{1}$, PENG Fei $^{1}$, Tsugiyuki MASUNAGA ${ }^{2}$, WANG Tao ${ }^{3}$, \\ LI Rui ${ }^{4}$ \\ ${ }^{1}$ Arid Land Research Center, Tottori University, Tottori 680-0001, Japan; \\ ${ }^{2}$ Life and Environmental Science, Shimane University, Matsue 690-8504, Japan; \\ ${ }^{3}$ Key Laboratory of Desert and Desertification, Northwest Institute of Eco-Environment and Resources, Chinese Academy of \\ Sciences, Lanzhou 730000, China; \\ ${ }^{4}$ State Key Laboratory of Remote Sensing Science, Institute of Remote Sensing and Digital Earth, Chinese Academy of Sciences, \\ Beijing 100101, China
}

\begin{abstract}
Soil salinization is a serious ecological and environmental problem because it adversely affects sustainable development worldwide, especially in arid and semi-arid regions. It is crucial and urgent that advanced technologies are used to efficiently and accurately assess the status of salinization processes. Case studies to determine the relations between particular types of salinization and their spectral reflectances are essential because of the distinctive characteristics of the reflectance spectra of particular salts. During April 2015 we collected surface soil samples $(0-10 \mathrm{~cm}$ depth) at 64 field sites in the downstream area of Minqin Oasis in Northwest China, an area that is undergoing serious salinization. We developed a linear model for determination of salt content in soil from hyperspectral data as follows. First, we undertook chemical analysis of the soil samples to determine their soluble salt contents. We then measured the reflectance spectra of the soil samples, which we post-processed using a continuum-removed reflectance algorithm to enhance the absorption features and better discriminate subtle differences in spectral features. We applied a normalized difference salinity index to the continuum-removed hyperspectral data to obtain all possible waveband pairs. Correlation of the indices obtained for all of the waveband pairs with the wavebands corresponding to measured soil salinities showed that two wavebands centred at wavelengths of 1358 and $2382 \mathrm{~nm}$ had the highest sensitivity to salinity. We then applied the linear regression modelling to the data from half of the soil samples to develop a soil salinity index for the relationships between wavebands and laboratory measured soluble salt content. We used the hyperspectral data from the remaining samples to validate the model. The salt content in soil from Minqin Oasis were well produced by the model. Our results indicate that wavelengths at 1358 and $2382 \mathrm{~nm}$ are the optimal wavebands for monitoring the concentrations of chlorine and sulphate compounds, the predominant salts at Minqin Oasis. Our modelling provides a reference for future case studies on the use of hyperspectral data for predictive quantitative estimation of salt content in soils in arid regions. Further research is warranted on the application of this method to remotely sensed hyperspectral data to investigate its potential use for large-scale mapping of the extent and severity of soil salinity.
\end{abstract}

Keywords: salinity index; soil salt content; spectral reflectance; waveband pairs; arid regions

Citation: QIAN Tana, Atsushi TSUNEKAWA, PENG Fei, Tsugiyuki MASUNAGA, WANG Tao, LI Rui. 2019. Derivation

*Corresponding author: QIAN Tana (E-mail: qian.tana@gmail.com)

Received 2017-12-29; revised 2018-04-03; accepted 2018-05-17

C Xinjiang Institute of Ecology and Geography, Chinese Academy of Sciences, Science Press and Springer-Verlag GmbH Germany, part of Springer Nature 2019 
of salt content in salinized soil from hyperspectral reflectance data: A case study at Minqin Oasis, Northwest China. Journal of Arid Land, 11(1): 111-122. https://doi.org/ 10.1007/s40333-019-0091-9

\section{Introduction}

Soil salinization is the most common type of land degradation encountered in natural resource management in many parts of the world and has received much attention from farmers, politicians and researchers (Wild, 2003; Farifteh et al., 2006; Rengasamy, 2006; Sheng et al., 2010; Wang et al., 2018). As one of the primary inhibitors of crop yield and ecological functions, soil salinity might ultimately lead to environmental disaster and food crises in arid regions (Munns, 2002; Barrett-Lennard, 2003). In China, the area of salt-affected land $\left(3.6 \times 10^{7} \mathrm{hm}^{2}\right)$ accounts for $4.88 \%$ of the country's total available land resource (Li et al., 2014; Zhang, 2014). Given the broad distribution of land salinization in China, it poses a severe threat to the sustainability of regional agriculture (Li et al., 2014).

Soil salinization in China occurs mainly in arid and semi-arid areas in the northwest regions, where low precipitation is coupled with intensive evapotranspiration. The strong evapotranspiration and the ineffective irrigation drainage systems have resulted in the secondary salinization (Ma et al., 2005; Wang et al., 2008). Minqin Oasis, one of the most fragile oasis in Northwest China, suffers a great shortage of fresh water for agriculture because of the low precipitation and massive demand for water created by increased agricultural activity and rapid population growth. Groundwater has been over-exploited to fill the gap between surface freshwater supply and demand (Bondes and Li, 2013; Wei et al., 2016). Groundwater extraction provides shortterm relief from the scarcity of water for agricultural and domestic use, but excessive extraction lowers the water table and increases salt content in groundwater (Chen et al., 2016). Long-term agricultural use of saline water has led to a rapid increase of secondary salinization at Minqin Oasis (Chen et al., 2016; Qian et al., 2017). For example, the total area of saline land within Minqin Oasis increased by $541.35 \mathrm{~km}^{2}$ from 1991 to 2009 (Xiao et al., 2007; Zhang et al., 2014). The persistent water scarcity and adverse effects of secondary salinization on crop yields led to a cropland abandonment of about $780 \mathrm{hm}^{2}$ (equal to $81 \%$ of area under cultivation) at two villages at Minqin Oasis in 2003 (Ma et al., 2007).

The combined effects of spatiotemporal variations of natural conditions (e.g., availability of irrigation water) and the seasonal and annual changes of agricultural practices have made it difficult to reduce the rate of salinization at the regional level in China. Accurate estimates of the areal extent of salinized land and prediction of areas likely to become saline are essential for policy makers, planners and farmers to allow effective management of irrigated land, control of salinization and reversal of current trends of soil and water degradation. Thus, it is crucially important to monitor soil salinity and assess its severity to prevent further degradation of agricultural land (Weng et al., 2010). Because the conventional methods of monitoring salinity by using ground-based geophysical techniques are time-consuming and costly (Dehaan and Taylor, 2003), a number of researchers have attempted to develop more cost-effective approaches to monitor current status of soil salinization and to predict future salinization by using multispectral or hyperspectral reflectance remote sensing techniques. The basis for monitoring the soil salinization is the distinct reflectance of different minerals (Mougenot et al., 1993; Metternicht and Zinck, 2003). Single or multiple wavebands have been selected and mathematically combined (e.g., division and subtraction) into indices to develop models that can be used to monitor large spatial scale of soil salinization (Douaoui et al., 2006; Fernandez-Bucs et al., 2006; Farifteh et al., 2007; Ding et al., 2011).

Comparing with multispectral data, hyperspectral reflectance data can capture subtle differences in soil properties and provide quick indirect assessments of soil characteristics due to the high spectral resolution (10-20 nm) and hundreds of available bands (Ben-Dor and Banin, 1995; Dwivedi, 2001; Farifteh et al., 2006; Gomez et al., 2008; Haubrock et al., 2008a; Zornoza et al., 2008; Ben-Dor et al., 2009; Goetz, 2009). Additionally, due to the ability of providing quantitative information about the particular salt minerals in soils, the development of methods that use 
hyperspectral data to estimate soil salinity has been the objective of many studies during the past two decades (Farifteh et al., 2006; Gomez et al., 2008; Haubrock et al., 2008b; Lu et al., 2013). Howari et al. (2002) assessed the spectral reflectance of soils treated with saline solutions containing $\mathrm{NaCl}, \mathrm{NaHCO}_{3}, \mathrm{NaSO}_{4}$, and $\mathrm{CaSO}_{4} \cdot \mathrm{H}_{2} \mathrm{O}$ in the laboratory to identify the presence of primary diagnostic spectral features of salt crusts. In addition, the sensitive bands for soil salt estimation vary with the predominant chemical compounds (salt mineralogy) in saline soils (Metternicht and Zinck, 2003; Farifteh et al., 2008; Wang et al., 2012; Fan et al., 2015).

The aim of this study was to estimate the salt content of soils from laboratory-derived hyperspectral data with a linear model. For this purpose, firstly, soil salinity and spectra data were statistically analysed to find optimal wavebands for deriving salt contents in soils. Secondly, a normalized difference spectral index that integrates the optimal wavebands was used to develop a predictive model for estimating the soil salt content from hyperspectral data.

\section{Methods}

\subsection{Study area}

The Minqin Oasis $\left(38^{\circ} 09^{\prime}-39^{\circ} 05^{\prime} \mathrm{N}, 102^{\circ} 24^{\prime}-103^{\circ} 49^{\prime} \mathrm{E}\right)$ is near the border of Gansu Province and Inner Mongolia Autonomous Region in Northwest China. It is bounded to the west by the Badain Jaran Desert and to the east by the Tengger Desert. This part of China has a temperate continental arid climate with a mean annual precipitation of $110 \mathrm{~mm}$ and annual evaporation of $2623 \mathrm{~mm}$. The annual mean temperature is $7.8^{\circ} \mathrm{C}$ with the monthly means ranging from $-8.6^{\circ} \mathrm{C}$ in January to $21.8^{\circ} \mathrm{C}$ in August. The annual mean wind velocity is $2.7 \mathrm{~m} / \mathrm{s}$, and wind force stronger than Beaufort scale $8(17.2-20.7 \mathrm{~m} / \mathrm{s})$ occurs $28 \mathrm{~d}$ per year on average. According to the genetic soil classification of China (Shi et al., 2006), the natural soils include grey-brown desert soil, aeolian sandy soil and saline soil. Cultivated soils are mainly irrigated desert soil and fluvo-aquic soils.

The Shiyang River originates from the Qilian Mountains and is the only source of fresh water in Minqin Oasis, which is covered largely by croplands that are heavily reliant on irrigation water from the river. The oasis is divided into five sub-regions: Huqu, Baqu, Shoucheng, Hongsha Liang and Quanshanqu. Our study area is the Huqu sub-region $\left(38^{\circ} 42^{\prime}-39^{\circ} 05^{\prime} \mathrm{N}, 103^{\circ} 25^{\prime}-103^{\circ} 49^{\prime} \mathrm{E}\right)$ at the northern margin of Minqin Oasis (Fig. 1). The sub-region includes the terminal lake of the Shiyang River. Thus, it is an area with long-term salt accumulation. The location of the sub-region and the inappropriate irrigation practices led to protracted and severe groundwater mineralization, soil salinization and desertification, such that most of the croplands are no longer to sustain grain crops. Substantial cropping areas have been abandoned because of the low productivity caused by the groundwater mineralization (groundwater mineralization $>3.0 \mathrm{~g} / \mathrm{L}$ can cause yield reductions of $>10 \%$ ) (Xiao et al., 2007).

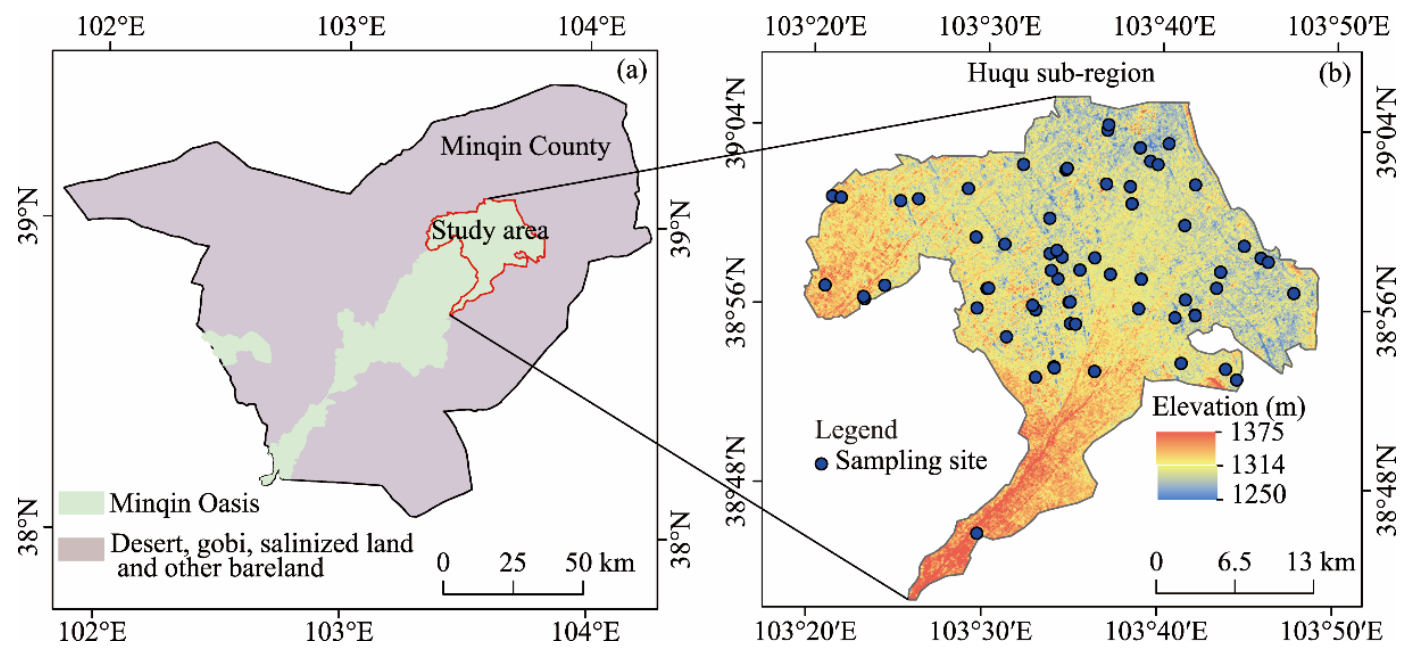

Fig. 1 Location of Minqin Oasis (a) and the sampling sites in the study area, Huqu sub-region (b) 


\subsection{Sampling and laboratory analysis}

The field work was conducted in Huqu sub-region in April 2015 when salt content in the surface soils reach the annual maximum. Soil samples were collected from the upper soil layer $(0-10 \mathrm{~cm}$ depth) at 64 sites (Fig. 1). At each sampling site, we collected soil samples at five randomly selected locations within a $30 \mathrm{~m} \times 30 \mathrm{~m}$ square and mixed the five samples thoroughly in the laboratory to represent the soil of that area. To determine the coordinates of the samples we used a handheld GPS receiver (MAP64SJZ, Garmin Ltd., Longmont, CO, USA).

The samples were taken to the Key Laboratory of Desert and Desertification at the Northwest Institute of Eco-Environment and Resources, Chinese Academy of Sciences, for chemical analysis and spectral reflectance measurement. Samples were air-dried, ground and sieved (1-mm mesh) to remove large particles and plant residues. They were then analysed for electrical conductivity, $\mathrm{pH}$, organic matter content $(\mathrm{OMC})$, and soluble salt content $\left(\mathrm{Na}^{+}, \mathrm{K}^{+}, \mathrm{Ca}^{2+}, \mathrm{Mg}^{2+}, \mathrm{Cl}^{-}, \mathrm{SO}_{4}{ }^{2-}, \mathrm{CO}_{3}{ }^{2-}\right.$ and $\mathrm{HCO}_{3}{ }^{-}$). The electrical conductivity was measured using soil over water mass ratio of 1:5. The $\mathrm{pH}$ was measured using soil over water mass ratio of 1:1 (Thomas et al., 1996). The amounts of $\mathrm{Na}^{+}, \mathrm{K}^{+}, \mathrm{Ca}^{2+}, \mathrm{Mg}^{2+}, \mathrm{Cl}^{-}$and $\mathrm{SO}_{4}{ }^{2-}$ in samples were measured using an ion chromatograph (Dionex ICS-900, Thermo Fisher Scientific Inc., Waltham, USA). Amounts of $\mathrm{CO}_{3}{ }^{2-}$ and $\mathrm{HCO}_{3}{ }^{-}$were measured using the double indicator titration method. The total soluble salt content (SSC) of each sample was determined on the basis of the total mass of the eight ionic concentrations (Bao, 2000). The soil samples were further sieved to isolate the $<0.1-\mathrm{mm}$ size fraction to measure organic carbon content (OCC).

To determine the spectral characteristics of different levels of soil salinity, we divided the spectra of the 64 soil samples into five salinity ranges as follows: 8 samples, 4-10 g/kg; 14 samples, 10 $21 \mathrm{~g} / \mathrm{kg}$; 9 samples, 21-30 g/kg; 19 samples, 30-40 g/kg; and 14 samples, 40-52 g/kg (Wang, 1993).

\subsection{Spectral data measurements}

Spectral measurements were conducted in a dark room with one halogen lamp (Lowel Light Pro, JCV 14.5V-70WC) illuminating the sample from a nadir position $20 \mathrm{~cm}$ to ensure stable atmospheric and uniform illumination conditions (Zhang et al., 2013). We used a spectroradiometer (FieldSpec 4, Analytical Spectral Devices Inc., Longmont, USA) to acquire reflectance spectra of the soil samples at wavelengths between 350 and $2500 \mathrm{~nm}$. The spectroradiometer uses individual detector arrays to record spectra at VNIR (350-1050 nm), SWIR1 (1000-1800 nm) and SWIR2 (1800-2500 nm) wavelengths. Sampling intervals were $1.4 \mathrm{~nm}$ for wavelengths $350-1000 \mathrm{~nm}$ (spectral resolution $3.0 \mathrm{~nm}$ ) and $2.0 \mathrm{~nm}$ for wavelengths $1000-2500 \mathrm{~nm}$ (spectral resolution 10.0 $\mathrm{nm}$ ); thus, spectral resolution varied from $3.0 \mathrm{~nm}$ for the shortest wavelengths to $10.0 \mathrm{~nm}$ for the longest wavelengths (Danner et al., 2015).

Reflectance data were collected using a fibre optic probe with a $25^{\circ}$ field of view that was installed on a tripod about $30 \mathrm{~cm}$ above the target and at about $15^{\circ}$ off nadir, which provided an observed surface area of $177 \mathrm{~cm}^{2}$. Each soil sample was filled to overflowing in a Petri dish $(10 \mathrm{~cm}$ diameter, $1 \mathrm{~cm}$ thick) and the upper surface was scraped off to provide a flat surface (Zhang, 2014). To minimize instrument noise, the reflectance were measured for 20 times and averaged to obtain the mean spectra for each soil sample. Before each measurement, reflectance was calibrated against a white reference panel of known reflectance (LapSphere Spectralon Diffuse Reflectance Panel) (Farifteh et al., 2008).

\subsection{Spectrum data processing}

Sensory errors inherent in the analytical spectral devices (ASD) spectroradiometer caused splices at around 1000 and $1800 \mathrm{~nm}$. These errors were corrected by applying the ASD ViewSpecPro program to smooth the "splices" between detector array domains (Danner et al., 2015).

A continuum-removal (CR) algorithm (ENVI image processing package, Research Systems Inc., Boulder, USA) was applied to all of the saline soil spectra that we measured to enhance small absorption features and better discriminate subtle differences in spectral features among samples (Clark and Roush, 1984; Huang et al., 2004). The continuum is a convex "hull" of line segments 
fitted along the top of a spectrum curve to connect local spectral maximums and represents the baseline. Against the baseline, more subtle absorption features are evident (Clark and Roush, 1984; Huang et al., 2004; Farifteh et al., 2008). The reflectance value at each point in an absorption feature was divided by the reflectance level of the corresponding convex hull to remove continuums for each waveband; the resulting ratio is known as CR-reflectance (Huang et al., 2004). We also determined a mean spectrum of CR-reflectance to represent the basic spectral characteristics of the five ranges of soil salinity defined in Section 2.2.

\subsection{Selection of sensitive bands}

We developed a normalized difference salinity index (NDSI; Eq. 1) to predict soil salinity from CR-reflectance data.

$$
\mathrm{NDSI}_{i, j, n}=\left(\mathrm{CRR}_{i, n}-\mathrm{CRR}_{j, n}\right) /\left(\mathrm{CRR}_{i, n}+\mathrm{CRR}_{j, n}\right),
$$

where $n$ is the number of soil samples and CRR is the CR-reflectance of sample $n$ for arbitrary wavebands $i$ and $j$.

The NDSI, composed of two arbitrary waveband components in the 350-2500 nm (2151 wavebands in total) wavelength range, provided 2,312,325 candidate pairs for the 64 samples. Using one pair of waveband, the 64 samples obtained 64 NDSI values. For the 64 samples, the correlation analysis (Eq. 2) was then applied to the NDSI and SSC; we likewise used correlation analysis to evaluate the relationships between the candidate NDSI waveband pairs and the known SSC.

$$
r=\frac{\sum_{i=1}^{n}\left(\mathrm{NDSI}_{i, j}-\overline{\mathrm{NDSI}_{i, j}}\right)\left(\mathrm{SSC}_{i}-\overline{\mathrm{SSC}}\right)}{\sqrt{\sum_{i=1}^{n}\left(\mathrm{NDSI}_{i, j}-\overline{\mathrm{NDSI}_{i, j}}\right)^{2} \sum_{i=1}^{n}\left(\mathrm{SSC}_{i}-\overline{\mathrm{SSC}}\right)^{2}}},
$$

where $r$ is the correlation coefficient between NDSI and SSC, $n$ is the number of soil samples, $\mathrm{NDSI}_{i, j}$ is the CR-reflectance of the spectrum for the $j^{\text {th }}$ band of the $i^{\text {th }}$ sample, $\mathrm{SSC}_{i}$ is the soluble salt content of the $i^{\text {th }}$ sample, and $\overline{\mathrm{NDSI}_{i, j}}$ and $\overline{\mathrm{SSC}}$ are the means of NDSI and soluble salt content, respectively.

The correlation coefficients between SSC values and all possible candidate NDSI were used to evaluate the contribution of NDSI to the estimation of soil salinity. The pair of bands with the highest correlation coefficient were taken to be the pair with the greatest sensitivity to soil salinity.

\subsection{Modelling the relationship between NDSI and SSC}

Among the 64 soil samples, we used 33 samples to establish a linear model of the relationship between NDSI and SSC by univariate regression with measured SSC as the dependent variable and NDSI as the independent variable. The measured SSC of the remaining 31 samples were used to validate the model.

\section{Results and discussion}

\subsection{Descriptive statistics of soil chemical properties}

Descriptive statistics on the chemical properties of the 64 soil samples are presented in Table 1 . The soil samples showed a broad range of salinity from 4.07 to $51.26 \mathrm{~g} / \mathrm{kg}$ (median, $31.54 \mathrm{~g} / \mathrm{kg}$ ). The predominant anions in the samples were $\mathrm{SO}_{4}{ }^{2-}$ and $\mathrm{Cl}^{-}$and the predominant cations were $\mathrm{Na}^{+}$ and $\mathrm{Ca}^{2+}$.

The correlation coefficients were 0.295 between $\mathrm{SO}_{4}{ }^{2-}$ and $\mathrm{Na}^{+}, 0.800$ between $\mathrm{Cl}^{-}$and $\mathrm{Na}^{+}$, and 0.789 between $\mathrm{Cl}^{-}$and $\mathrm{Ca}^{2+}$ (Table 2). There were also strong correlations of SSC with $\mathrm{Ca}^{2+}$ $(r=0.854), \mathrm{Cl}^{-}(r=0.695)$ and $\mathrm{SO}_{4}{ }^{2-}(r=0.587)$. Thus, it is likely that most of the chemical compounds in the soil samples are chlorine and sulphate compounds.

Although both $\mathrm{K}^{+}$and $\mathrm{Mg}^{2+}$ showed strong positive relationships with $\mathrm{Cl}^{-}$and $\mathrm{SSC}$, which might indicate the presence of $\mathrm{KCl}$ or $\mathrm{MgCl}_{2}$, their very low mean concentrations $(0.15$ and $0.29 \mathrm{~g} / \mathrm{kg}$ for 
$\mathrm{K}^{+}$and $\mathrm{Mg}^{2+}$, respectively) indicate that $\mathrm{KCl}$ and $\mathrm{MgCl}_{2}$ were not dominant salts in the soil samples.

There were very low contents of $\mathrm{HCO}_{3}{ }^{-}$in the soil samples and no $\mathrm{CO}_{3}{ }^{2-}$ was identified, which together indicate that there was little in the way of bicarbonate compounds and no discernible carbonate compounds in the soils.

The dominant anions in each of the five salinity ranges were $\mathrm{SO}_{4}{ }^{2-}$ and $\mathrm{Cl}^{-}$(Fig. 2). The concentration of bicarbonate decreased with increasing soil salinity. As soil salinity increased, $\mathrm{Na}^{+}$ became the dominant cation for the SSC ranges of $21-30,30-40$ and $40-52 \mathrm{~g} / \mathrm{kg}$. The concentrations of $\mathrm{Ca}^{2+}$ were relatively high for all salinity ranges, which indicates that the dominant salts were probably $\mathrm{CaSO}_{4}$ and $\mathrm{CaCl}_{2}$ for the lower salinity samples (SSC of 4-10 and 10-21 g/kg).

Table 1 Descriptive statistics of chemical properties of the 64 soil samples

\begin{tabular}{|c|c|c|c|c|c|c|c|c|c|c|c|}
\hline \multirow{2}{*}{ Statistic } & $\mathrm{Na}^{+}$ & $\mathrm{K}^{+}$ & $\mathrm{Mg}^{2+}$ & $\mathrm{Ca}^{2+}$ & $\mathrm{Cl}^{-}$ & $\mathrm{SO}_{4}{ }^{2-}$ & $\mathrm{HCO}_{3}^{-}$ & $\mathrm{CO}_{3}{ }^{2-}$ & \multirow{2}{*}{$\begin{array}{c}\mathrm{EC}_{1: 5} \\
(\mathrm{mS} / \mathrm{cm})\end{array}$} & $\mathrm{SSC}$ & OCC \\
\hline & \multicolumn{8}{|c|}{$(\mathrm{g} / \mathrm{kg})$} & & \multicolumn{2}{|c|}{$(\mathrm{g} / \mathrm{kg})$} \\
\hline Max & 20.84 & 0.51 & 2.07 & 4.76 & 17.80 & 40.56 & 0.34 & 0.00 & 22.36 & 51.26 & 7.36 \\
\hline Min & 0.00 & 0.03 & 0.01 & 0.05 & 0.68 & 2.37 & 0.01 & 0.00 & 0.14 & 4.07 & 2.22 \\
\hline Mean & 4.13 & 0.15 & 0.29 & 2.11 & 5.70 & 15.50 & 0.14 & 0.00 & 5.59 & 28.01 & 4.83 \\
\hline SD & 5.50 & 0.12 & 0.37 & 1.56 & 4.28 & 9.60 & 0.05 & 0.00 & 5.61 & 13.34 & 1.16 \\
\hline $\mathrm{CV}$ & 1.33 & 0.77 & 1.30 & 0.74 & 0.75 & 0.62 & 0.39 & 0.00 & 1.00 & 0.48 & 0.24 \\
\hline
\end{tabular}

Note: SD, standard derivation; $\mathrm{CV}$, coefficient of variance (ratio of standard derivation to the mean); $\mathrm{EC}_{1: 5}$, electrical conductivity at a soil water ratio of 1:5; SSC, soluble salt content; OCC, organic carbon content.

Table 2 Correlation matrix of relationships between variables

\begin{tabular}{|c|c|c|c|c|c|c|c|c|c|}
\hline & $\mathrm{Na}^{+}$ & $\mathrm{K}^{+}$ & $\mathrm{Mg}^{2+}$ & $\mathrm{Ca}^{2+}$ & $\mathrm{Cl}^{-}$ & $\mathrm{SO}_{4}{ }^{2-}$ & $\mathrm{HCO}_{3}^{-}$ & $\mathrm{EC}_{1: 5}$ & $\mathrm{SSC}$ \\
\hline $\mathrm{Na}^{+}$ & 1.000 & & & & & & & & \\
\hline $\mathrm{K}^{+}$ & $0.815^{* *}$ & 1.000 & & & & & & & \\
\hline $\mathrm{Mg}^{2+}$ & $0.668^{* *}$ & $0.550^{* *}$ & 1.000 & & & & & & \\
\hline $\mathrm{Ca}^{2+}$ & $0.782^{* *}$ & $0.759^{* *}$ & $0.661^{* *}$ & 1.000 & & & & & \\
\hline $\mathrm{Cl}^{-}$ & $0.800^{* *}$ & $0.724^{* *}$ & $0.718^{* *}$ & $0.789^{* *}$ & 1.000 & & & & \\
\hline $\mathrm{SO}_{4}{ }^{2-}$ & $-0.285^{*}$ & -0.108 & -0.128 & 0.195 & -0.100 & 1.000 & & & \\
\hline $\mathrm{HCO}^{3-}$ & -0.049 & 0.140 & 0.004 & -0.006 & 0.110 & -0.125 & 1.000 & & \\
\hline $\mathrm{EC}_{1: 5}$ & $0.961^{* *}$ & $0.795^{* *}$ & $0.717^{* *}$ & $0.806^{* *}$ & $0.817^{* *}$ & -0.230 & -0.062 & 1.000 & \\
\hline $\mathrm{SSC}$ & $0.579^{* *}$ & $0.601^{* *}$ & $0.522^{* *}$ & $0.854^{* *}$ & $0.695^{* *}$ & $0.587^{* *}$ & -0.074 & $0.611^{* *}$ & 1.000 \\
\hline
\end{tabular}

Note: ${ }^{* *}$, significant at the 0.01 probability level (2-tailed); ${ }^{*}$, significant at the 0.05 probability level (2-tailed).

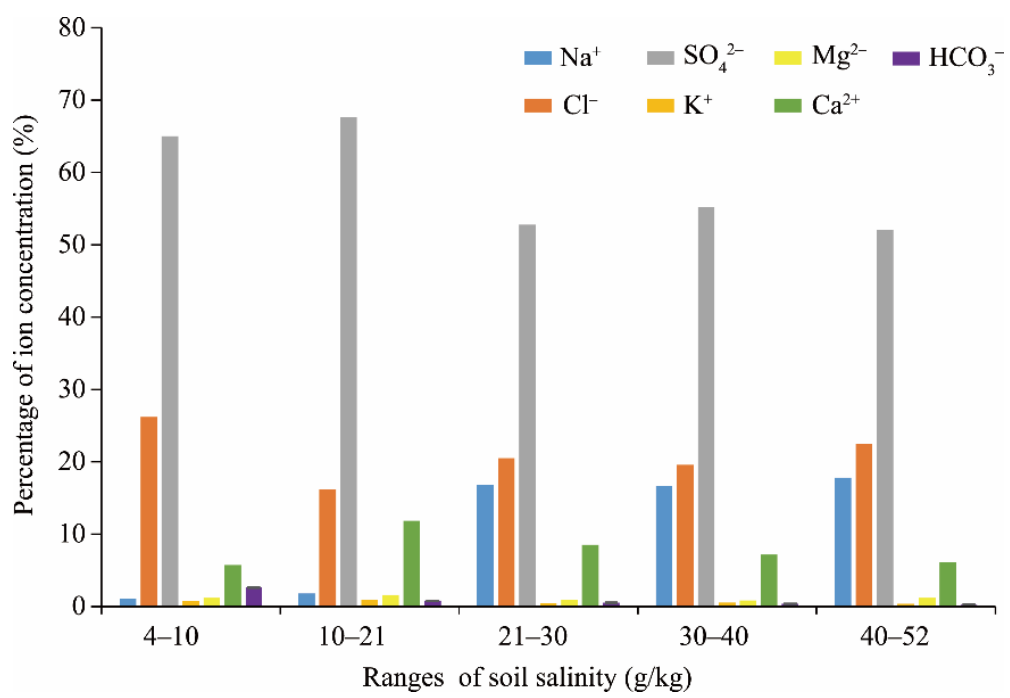

Fig. 2 Concentrations of $\mathrm{Na}^{+}, \mathrm{K}^{+}, \mathrm{Ca}^{2+}, \mathrm{Mg}^{2+}, \mathrm{Cl}^{-}, \mathrm{SO}_{4}{ }^{2-}$ and $\mathrm{HCO}_{3}{ }^{-}$ions for different ranges of soil salinity. The percentage of ion concentration was calculated by dividing the concentration of certain ion by the total cation and anion concentration of the corresponding soil salinity range. 
For the higher salinity ranges (SSC of 21-30, 30-40, 40-52 g/ kg), the dominant salts were probably $\mathrm{NaCl}, \mathrm{CaSO}_{4}, \mathrm{CaCl}_{2}$ and $\mathrm{NaSO}_{4}$. Concentrations of $\mathrm{Ca}^{2+}$ initially increased with increasing soil salinity up to $20 \mathrm{~g} / \mathrm{kg}$, but then decreased with further increases of salinity. The concentration of $\mathrm{HCO}_{3}{ }^{-}$decreased as soil salinity increased across the entire salinity range (Fig. 2).

\subsection{Spectral features of soil samples}

The spectra of all 64 samples were of similar shapes with considerable overlap (Fig. 3a). The representative spectra for the five ranges of salinity (Fig. 3b) exhibited several differences in the width of reflectance peaks and depth of absorption troughs. CR-processing of the spectra strengthened the peaks and troughs of these spectra (Figs. 3c and d). The spectra for samples in each of the five salinity ranges showed similar absorption features at wavelengths of about 1400 , 1900 and $2200 \mathrm{~nm}$. These features are associated with the particular salts in the soils and are related to the internal vibrational processes of anions (e.g., $\mathrm{OH}^{-}, \mathrm{SO}_{4}{ }^{2-}$ and the $\mathrm{Al}-\mathrm{OH}$ group) or to water
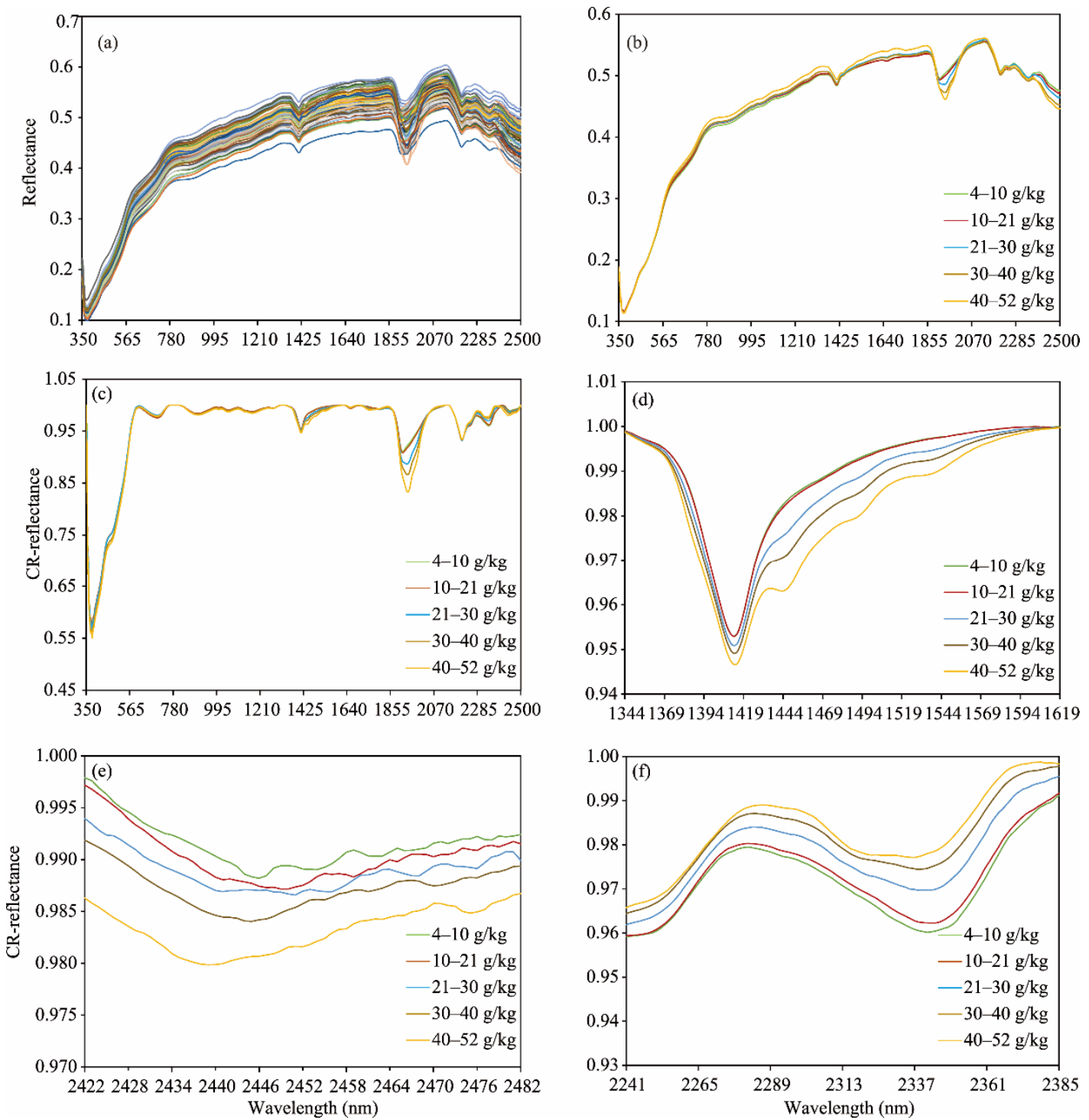

Fig. 3 Reflectance spectra: (a) original measured spectra of all 64 soil samples, (b) averaged spectra of samples in five salinity ranges, (c) CR-reflectance spectra of samples in five salinity ranges, (d) enlargement of panel for range of 1344-1619 nm, (e) enlargement of panel for range of 2422-2482 nm, and (f) enlargement of panel for range of $2241-2385 \mathrm{~nm}$. 
molecules that are trapped in or adsorbed on the crystal structure (Hunt, 1977; Crowley, 1991). The internal vibrational processes of the anion groups were the result of overtones or combinations (stretching and bending modes) of fundamental vibrations and of vibrations of the entire lattice (Hunt, 1977; Mougenot et al., 2009). The broad absorption features near 1400, 1940 and $2250 \mathrm{~nm}$ are probably related to fluid inclusions in halite $(\mathrm{NaCl})$ after drying (Clark and Roush, 1984; Crowley, 1991; Danner et al., 2015). The features near 2200, 2300 and $2400 \mathrm{~nm}$ probably represent $\mathrm{O}-\mathrm{H}$ stretch, $\mathrm{AlOH} / \mathrm{MgOH}$ bending mode, or the combined effect of both. Previous research has shown that these salt minerals (e.g., chlorine compounds) are the dominant evaporites that form crystals or efflorescence in salinized crusts and scalds in arid regions (Farifteh et al., 2008). Moreover, previous researchers suggested that absorption features at around 1000, 1200, 1400, 1600, 1740, 1900, 2200 and $2330 \mathrm{~nm}$ might also be affected by combination overtones of O-H stretching, $\mathrm{H}-\mathrm{O}-\mathrm{H}$ bending fundamentals, and various overtones in gypsum $\left(\mathrm{CaSO}_{4} \cdot 2 \mathrm{H}_{2} \mathrm{O}\right)(\mathrm{Howari}$ et al., 2002).

In the range from 350 to $1000 \mathrm{~nm}$, no marked difference was distinguishable among the spectra for the five salinity ranges (Fig. 3c). At wavelengths higher than $1300 \mathrm{~nm}$, salinity-induced changes in soil reflectance were evident, particularly in the water absorption bands at around 1400 and 1900 $\mathrm{nm}$ (Fig. 3c). Reflectances of the lower salinity ranges were higher than those of the higher salinity ranges at about 1344-1619 nm (Fig. 3d) and 2422-2482 nm (Fig. 3e). In contrast, reflectances of the higher salinity ranges were higher than those of the lower salinity ranges near a small peak at 2241-2385 nm (Fig. 3f). The depths of the absorption troughs centred at about 1410 and $1940 \mathrm{~nm}$, increased with increasing salinity.

\subsection{Modeling of SSC and model validation}

Correlation of the wavebands of measured salinities of 64 samples with all of the waveband pairs used in the NDSI (Fig. 4) produced strong correlations (absolute value of $r>0.84$ ) for the following pairs: 750-920 and 2351-2487, 1199-1379 and 2351-2487, 1553-1765 and 2351-2487, and 21182261 and 2351-2487 nm (Fig. 4). Among these waveband pairs, the most promising sensitive waveband paires were 1199-1379 and 2351-2487 $\mathrm{nm}$. The bands including wavelengths 1358 and $2382 \mathrm{~nm}(r=-0.87)$ were identified as the most promising bands that can be used to develop a quantitative model for estimation of salt concentration from hyperspectral data.

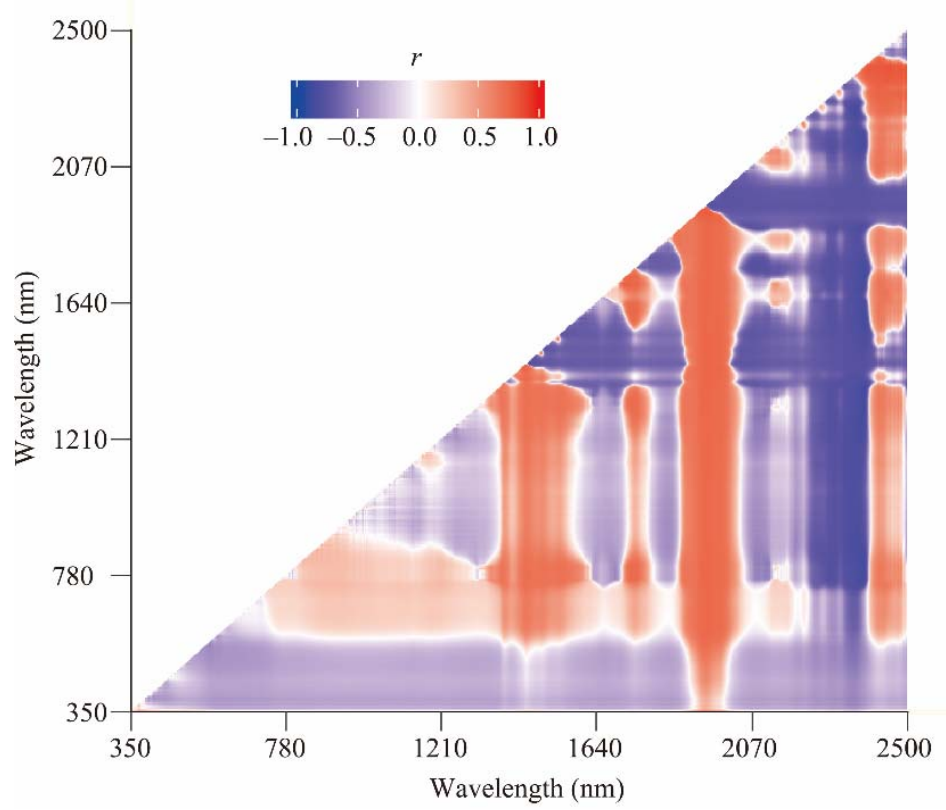

Fig. 4 Heatmap of correlation coefficients $(r)$ for measured salinitity with all candidate NDSI waveband pairs 
We therefore defined the following salinity spectral index (SSI):

$$
\mathrm{SSI}=(\mathrm{B} 2382-\mathrm{B} 1358) /(\mathrm{B} 2382+\mathrm{B} 1358),
$$

where B1358 and B2382 are CR-reflectances of spectral bands at 1358 and $2382 \mathrm{~nm}$, respectively.

The model established by univariate linear regression to estimate SSC from hyperspectral data (Fig. 5a) was expressed as,

$$
\mathrm{SSC}=5312.3 \times \mathrm{SSI}+34.187(r=0.8272) .
$$

Validation of the predicted values of SSC against measured values (Fig. 5b) showed that Equation 5 over-estimated SSC, which we attributed to the presence in our samples of some salt ions (e.g., $\mathrm{Fe}$ and $\mathrm{Al}$ ) that were not measured during laboratory analysis.
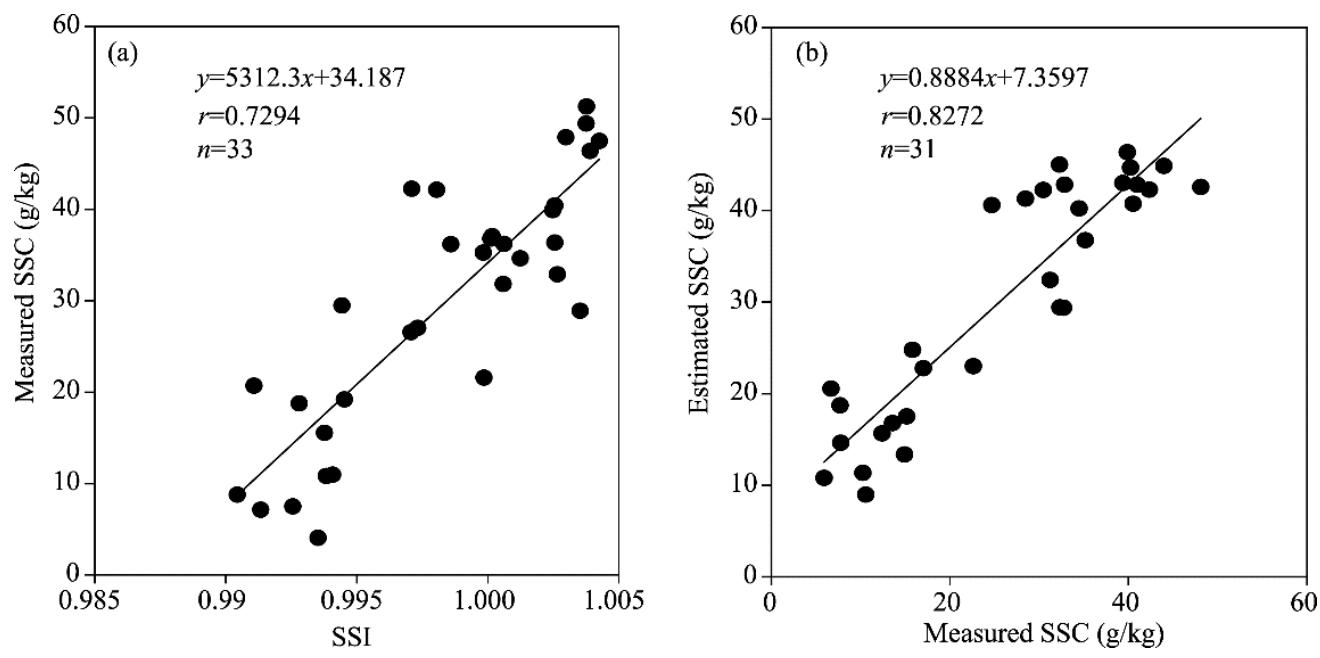

Fig. 5 (a) Measured soluble salt content (SSC) versus salinity spectral index (SSI) and (b) scatter plots of measured SSC versus SSC estimated from Equation 5

To ascertain which soluble salts the CR-reflectance wavelengths were responsive to, we examined the relationships of ionic concentrations $\left(\mathrm{Na}^{+}, \mathrm{K}^{+}, \mathrm{Ca}^{2+}, \mathrm{Mg}^{2+}, \mathrm{Cl}^{-}, \mathrm{SO}_{4}{ }^{2-}, \mathrm{CO}_{3}{ }^{2-}\right.$ and $\mathrm{HCO}_{3}{ }^{-}$) in the 64 samples with the CR-reflectances at 2382 and $1358 \mathrm{~nm}$, and with the SSI (Fig. $6)$. We found significant correlations between $\mathrm{Na}^{+}$and the CR-reflectances at $2382(r=0.622)$ and $1358 \mathrm{~nm}(r=-0.603)$, between $\mathrm{Na}^{+}$and SSI $(r=0.661)$, between $\mathrm{Cl}^{-}$and the CR-reflectances at 2382 $(r=0.683)$ and $1358 \mathrm{~nm}(r=-0.561)$, and between $\mathrm{Na}^{+}$and SSI $(r=0.711)$. Howari et al. (2002) reported that distinct absorption features for $\mathrm{CaSO}_{4} \cdot 2 \mathrm{H}_{2} \mathrm{O}$, mixture of $\mathrm{CaSO}_{4} \cdot 2 \mathrm{H}_{2} \mathrm{O}$ and $\mathrm{NaCl}$, and $\mathrm{NaHCO}_{3}$ were occurred at wavelengthes of 1199-1379 nm. For the wavelengthes of 2351-2487 $\mathrm{nm}$, absorption band position reported by Crowley (1991) and Howari et al. (2002) were related with $\mathrm{NaHCO}_{3}$ and $\mathrm{CaSO}_{4} \cdot 2 \mathrm{H}_{2} \mathrm{O}$. These results indicate that the two bands used in this study to construct the SSI were best suited for soils where the predominant soluble salts contain chlorine, sulphate and carbonate compounds. In contrast, in the Yellow River delta region of China where the dominant soluble salts are $\mathrm{NaCl}$ and $\mathrm{MgCl}_{2}, \mathrm{CR}$-reflectances at 2052 and $2203 \mathrm{~nm}$ were used to construct a spectral soil salinity index (Weng et al., 2010). In South Africa, where most of the salts in soils are of marine origin, reflectances at 2040 and $1410 \mathrm{~nm}$ were identified as the most promising for use in a spectral soil salinity index (Mashimbye, 2013). Considering our results and those from other regions, it is evident that particular salts influence spectral reflectance differently, so the wavelengths employed in developing SSI should be selected on a case by case basis, although a particular SSI may be applicable in areas with the same salt types as the area in which the SSI was developed. In addition, the lab measured spectral reflectance of air-dried soil samples avoid the interference of moisture content, surface roughness and vegetation, etc. Thus, the accuracy of soil salinity estimation has been improved. However, for remote sensing data based large-scale salinity monitoring, the spectra of saline soils vary largely with moisture content, roughness and other soil surface features, which may cause significant errors during soil salt content estimation. 


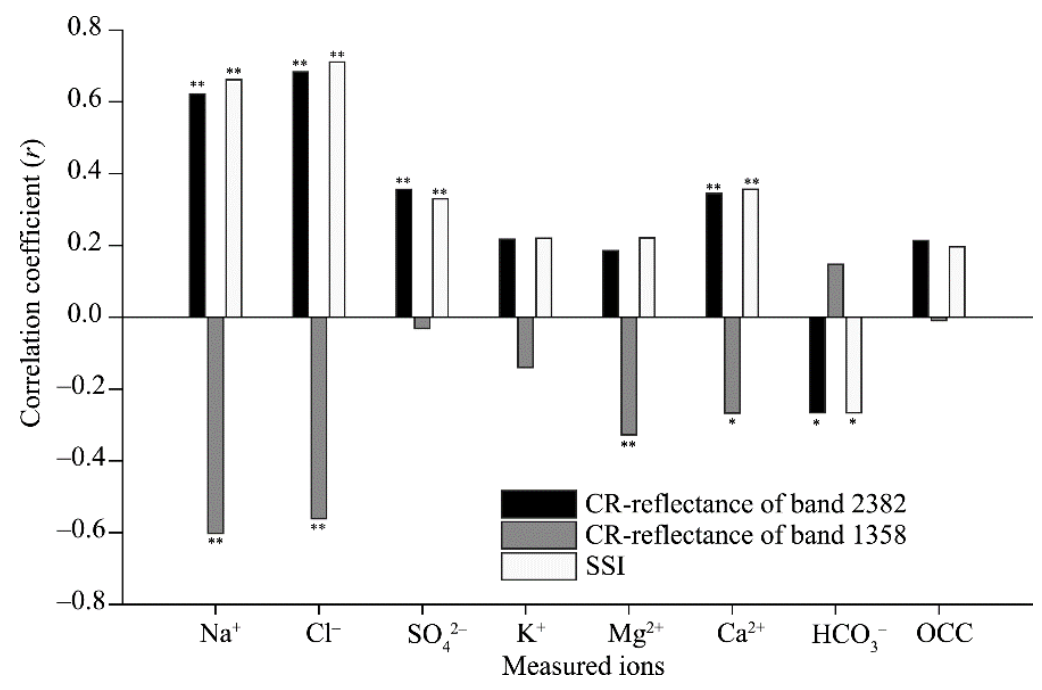

Fig. 6 Correlation coefficients $(r)$ obtained for measured concentrations of seven ions and organic carbon content (OCC) with the CR-reflectances at 2382 and $1358 \mathrm{~nm}$, and with the salinity spectral index (SSI). ${ }^{* *}$, correlation significant at the 0.01 probability level (2-tailed). ${ }^{*}$, correlation significant at the 0.05 probability level (2-tailed).

\section{Conclusions}

Statistical analysis of the measured soluble salt contents and the lab measured hyperspectral reflectance for all of the 64 soil samples showed that two wavebands centred at 2382 and $1358 \mathrm{~nm}$ were closely associated with sodium and chloride concentrations and thus were selected as optimal wavebands. NDSI was developed and used as the independent variable in the modelling process based on the optimal wavebands. The validation of the model showed a strong correlation $(r=0.8272)$. Thus, the model we derived successfully estimated the soluble salt content of surface soils in the study area in which the dominant salt types are chlorine and sulphate compounds. Further research is needed on the application of this method to remotely sensed (aircraft or satellite) digital hyperspectral data so that its potential use for large-scale predictive mapping of the extent and severity of soil salinity can be investigated.

\section{Acknowledgements}

This research was supported by the International Platform for Dryland Research and Education, Tottori University and the National Key R\&D Program of China (2016YFC0500909). The authors would like to thank Professor WEI Huaidong, Professor DING Feng and Professor ZHOU Liping from Gansu Desertification and Aeolian Sand Disaster Combating Institute for providing the equipment and assistance in the measurement; Professor XUE Xian, Professor WANG Ninglian, Dr. HUANG Cuihua, Dr. LIAO Jie, Dr. LUO Jun and Dr. DONG Siyang from Northwest Institute of Eco-Environment and Resources, Chinese Academy of Sciences, for providing the equipment and the assistance in the field work; and Professor Kitamura YOSHINOBU and Fujimaki HARUYUKI from Tottori University for their helpful advices and providing the equipment for experiments.

\section{References}

Bao S D. 2000. Soil Agricultural Chemistry Analysis. Beijing: China Agriculture Press, 178-198. (in Chinese)

Barrett-Lennard E G. 2003. The interaction between waterlogging and salinity in higher plants: causes, consequences and implications. Plant and Soil, 253(1): 35-54.

Ben-Dor E, Banin A. 1995. Near-infrared analysis as a rapid method to simultaneously evaluate several soil properties. Soil Science Society of America Journal, 59(2): 364-372.

Ben-Dor E, Chabrillat S, Demattê J A M, et al. 2009. Using imaging spectroscopy to study soil properties. Remote Sensing of Environment, 113(Suppl. 1): S38-S55.

Bondes M, Li D. 2013. Climate Change and Sustainable Development in Western China's Minqin Oasis: Joining Forces with 
Society. In: Vajpeyi D. Climate Change, Sustainable Development and Human Security. New York: Lexington, 139-168.

Chen L, Feng Q, Li C, et al. 2016. Spatial variations of soil microbial activities in saline groundwater-irrigated soil ecosystem. Environmental Management, 57(5): 1054-1061.

Clark R N, Roush T L. 1984. Reflectance spectroscopy: Quantitative analysis techniques for remote sensing applications. Journal of Geophysical Research: Solid Earth, 89(B7): 6329-6340.

Crowley J K. 1991. Visible and near-infrared $(0.4-2.5 \mu \mathrm{m})$ reflectance spectra of Playa evaporate minerals. Journal of Geophysical Research: Solid Earth, 96(B10): 16231-16240.

Danner M, Locherer M, Hank T, et al. 2015. Spectral Sampling with the ASD FieldSpec 4-Theory, Measurement, Problems, Interpretation. In: EnMAP Field Guides Technical Report. GFZ Data Services. Brandenburg, Germany.

Dehaan R, Taylor G R. 2003. Image-derived spectral endmembers as indicators of salinisation. International Journal of Remote Sensing, 24(4): 775-794.

Ding J L, Wu M C, Tiyip T. 2011. Study on soil salinization information in arid region using remote sensing technique. Agricultural Sciences in China, 10(3): 404-411.

Douaoui A E K, Nicolas H, Walter C. 2006. Detecting salinity hazards within a semiarid context by means of combining soil and remote-sensing data. Geoderma, 134(1-2): 217-230.

Dwivedi R S. 2001. Soil resources mapping: A remote sensing perspective. Remote Sensing Reviews, 20(2): 89-122.

Fan X, Liu Y, Tao J, et al. 2015. Soil salinity retrieval from advanced multi-spectral sensor with partial least square regression. Remote Sensing, 7(1): 488-511.

Farifteh J, Farshad A, George R J. 2006. Assessing salt-affected soils using remote sensing, solute modelling, and geophysics. Geoderma, 130(3-4): 191-206.

Farifteh J, Van der Meer F, Atzberger C, et al. 2007. Quantitative analysis of salt-affected soil reflectance spectra: A comparison of two adaptive methods (PLSR and ANN). Remote Sensing of Environment, 110(1): 59-78.

Farifteh J, Van der Meer F, Van der Meijde M, et al. 2008. Spectral characteristics of salt-affected soils: A laboratory experiment. Geoderma, 145(3-4): 196-206.

Femández-Bucs N, Siebe C, Cram S, et al. 2006. Mapping soil salinity using a combined spectral response index for bare soil and vegetation: A case study in the former lake Texcoco, Mexico. Journal of Arid Environments, 65(4): 644-667.

Goetz A F H. 2009. Three decades of hyperspectral remote sensing of the Earth: A personal view. Remote Sensing of Environment, 113(Suppl. 1): S5-S16.

Gomez C, Viscarra Rossel R A, McBratney A B. 2008. Soil organic carbon prediction by hyperspectral remote sensing and field vis-NIR spectroscopy: An Australian case study. Geoderma, 146(3-4): 403-411.

Haubrock S N, Chabrillat S, Kuhnert M, et al. 2008a. Surface soil moisture quantification and validation based on hyperspectral data and field measurements. Journal of applied remote sensing, 2(1): 1-26.

Haubrock S N, Chabrillat S, Lemmnitz C, et al. 2008b. Surface soil moisture quantification models from reflectance data under field conditions. International Journal of Remote Sensing, 29(1): 3-29.

Howari F M, Goodell P C, Miyamoto S. 2002. Spectral properties of salt crusts formed on saline soils. Journal of Environmental Quality, 31(5): 1453-1461.

Huang Z, Turner B J, Dury S J, et al. 2004. Estimating foliage nitrogen concentration from HYMAP data using continuum removal analysis. Remote Sensing of Environment, 93(1-2): 18-29.

Hunt G R. 1977. Spectral signatures of particulate minerals in the visible and near infrared. Geophysics, 42(3): 501-513.

Li J, Pu L, Han M, et al. 2014. Soil salinization research in China: Advances and prospects. Journal of Geographical Sciences, 24(5): 943-960.

Lu P, Wang L, Niu Z, et al. 2013. Prediction of soil properties using laboratory VIS-NIR spectroscopy and Hyperion imagery. Journal of Geochemical Exploration, 132(Suppl. C): 26-33.

Ma J Z, Wang X S, Edmunds W M. 2005. The characteristics of ground-water resources and their changes under the impacts of human activity in the arid Northwest China - a case study of the Shiyang River Basin. Journal of Arid Environments, 61(2): 277-295.

Ma Y, Fan S, Zhou L, et al. 2007. The temporal change of driving factors during the course of land desertification in arid region of North China: the case of Minqin County. Environmental Geology, 51(6): 999-1008.

Mashimbye Z E. 2013. Remote sensing of salt-affected soils. PhD Dissertation. Western Cape: Stellenbosch University, 98.

Metternicht G I, Zinck J A. 2003. Remote sensing of soil salinity: potentials and constraints. Remote Sensing of Environment, 85(1): 1-20.

Mougenot B, Pouget M, Epema G F. 1993. Remote sensing of salt affected soils. Remote Sensing Reviews, 7(3-4): 241-259.

Munns R. 2002. Comparative physiology of salt and water stress. Plant, Cell \& Environment, 25(2): 239-250. 
Qian T N, Tsunekawa A, Masunaga T, et al. 2017. Analysis of the Spatial Variation of Soil Salinity and Its Causal Factors in China's Minqin Oasis. Mathematical Problems in Engineering, Vol. 2017. https://doi.org/10.1155/2017/9745264.

Rengasamy P. 2006. World salinization with emphasis on Australia. Journal of Experimental Botany, 57(5): $1017-1023$.

Sheng J, Ma L, Jiang P, et al. 2010. Digital soil mapping to enable classification of the salt-affected soils in desert agro-ecological zones. Agricultural Water Management, 97(12): 1944-1951.

Shi X Z, Yu D S, Yang G X, et al. 2006. Cross-reference benchmarks for translating the Genetic Soil Classification of China into the Chinese Soil Taxonomy. Pedosphere, 16(2): 147-153.

Thomas G W. 1996. Soil pH and soil acidity. In: Sparks R S L, Swift D. L. Methods of Soil Analysis. Part 3-Chemical Methods. Madison: Soil Science Society of America, 475-490.

Wang Q, Li P, Chen X. 2012. Modeling salinity effects on soil reflectance under various moisture conditions and its inverse application: A laboratory experiment. Geoderma, 170: 103-111.

Wang Y, Li Y, Xiao D. 2008. Catchment scale spatial variability of soil salt content in agricultural oasis, Northwest China. Environmental Geology, 56(2): 439-446.

Wang Y, Deng C, Liu Y, et al. 2018. Identifying change in spatial accumulation of soil salinity in an inland river watershed, China. Science of the Total Environment, 621: 177-185.

Wang Z. 1993. Chinese Saline-Alkaline Soil. Beijing: Science Press, 335. (in Chinese)

Wei H, Li Y, Xu C D, et al. 2016. The process of cultivated land and water resource distribution changing in recent decades in upstream and downstream in Shiyang Inland River Basin in arid area of Northwest China. Journal of Geoscience and Environment Protection, 4(7): 166-171.

Weng Y, Gong P, Zhu Z. 2010. A spectral index for estimating soil salinity in the Yellow River Delta Region of China using EO1 Hyperion data. Pedosphere, 20(3): 378-388.

Wild A. 2003. Soils, Land and Food: Managing the Land during the Twenty-First Century. Cambridge: Cambridge University Press, 84-85.

Xiao D, Li X, Song D, et al. 2007. Temporal and spatial dynamical simulation of groundwater characteristics in Minqin Oasis. Science in China Series D: Earth Sciences, 50(2): 261-273.

Zhang F, Tiyip T, Ding J, et al. 2003. Studies on the reflectance spectral features of saline soil along the middle reaches of Tarim River: a case study in Xinjiang Autonomous Region, China. Environmental Earth Sciences, 69(8): 2743-2761.

Zhang J. 2014. Salt-affected soil resources in China. In: Zhang J F. Coastal Saline Soil Rehabilitation and Utilization Based on Forestry Approaches in China. Berlin: Springer Science \& Business Media, 9-13.

Zhang L F, Yang S W, Zhang M W. 2014. Study on land use change in arid and semiarid region based on GIS and RS. Information Technology Journal, 13(8): 1567-1571.

Zornoza R, Guerrero C, Mataix-Solera J, et al. 2008. Near infrared spectroscopy for determination of various physical, chemical and biochemical properties in Mediterranean soils. Soil Biology and Biochemistry, 40(7): 1923-1930. 